\title{
JARINGAN SYARAF TIRUAN PERCEPTRON UNTUK PENENTUAN POLA SISTEM IRIGASI LAHAN PERTANIAN DI KABUPATEN PESISIR SELATAN SUMATRA BARAT
}

\author{
Musli Yanto' ${ }^{1)}$ Rini Sovia ${ }^{2)}$, dan Eka Praja Wiyata Mandala ${ }^{3)}$ \\ ${ }^{1,2,3}$ Teknik Informatika, Fakultas Ilmu Komputer,Universitas Putra Indonesia "YPTK" Padang \\ 1,2,3 Jl. Raya Lubuk Begalung, Padang, 25121 \\ E-mail: musli_yanto@upiyptk.ac.id ${ }^{1)}$,rini_sovia4@gmail.com ${ }^{2)}$, ekaprajawm@upiyptk.ac.id ${ }^{3)}$
}

\begin{abstract}
ABSTRAK
Penelitian Jaringan Syaraf Tiruan dengan menggunakan algoritma Perceptron ini, akan digunakan dalam menyelesaikan kasus untuk menunjang sebuah keputusan pada pembangunan irigasi air di daerah Kabupaten Pesisir Selatan Provinsi Sumatera Barat. Metode Jaringan Syaraf Tiruan algoritma Perceptron adalah sebuah metode yang mampu melakukan proses perhitungan dengan mengenali variabel-variabel dalam pencocokan pola dan pada akhirnya hasil keluaran dari Jaringan dapat digunakan sebagai bahan pertimbangan pengambilan keputusan. Tujuan akhir dari penelitian ini adalah untuk membantu pihak Dinas Pengelolaan Sumber Daya Air Kabupaten Pesisir Selatan yang kesulitan dalam menentukan daerah mana yang seharusnya terlebih dahulu di prioritaskan untuk pembangunan sistem irigasi, sehingga pihak Dinas Pengelolaan Sumber Daya Air Kabupaten Pesisir Selatan cepat tanggap dalam memutuskan pembangunan sistem irigasi. Konsep pola Jaringan Syaraf Tiruan Algoritma Perceptron yang dihasilkan akan diterapakan kedalam Sistem pengambilan keputusan yang bermanfaat untuk mepermudah kinerja Dinas Pengelolaan Sumber Daya Air Kabupaten Pesisir Selatan dalam pengolahan dan penentuan keputusan pembangunan sistem irigasi.
\end{abstract}

Kata Kunci: Jaringan Syaraf Tiruan, Algoritma Perceptron, Variabel dan Keputusan

\section{PENDAHULUAN}

Perkembangan teknologi juga telah dirasakan pada bidang pertanian. Bentuk contoh pemanfaatan teknologi bisa dilihat dengan adanya sebuah sistem aplikasi yang mampu mengelola data-data yang berkaitan dengan bidang pertanian. Permasalahan yang akan dibahas dalam penelitian ini yakni permasalahan dalam memberikan keputusan dalam pembangunan sistem irigasi yang ada di daerah Kabupaten Pesisir Selatan Provinsi Sumatera Barat.

Permasalan yang bisa terlihat bahwa Dinas Pengelolaan Sumber Daya Air Kabupaten (PSDA) Pesisir Selatan adalah kesulitan untuk menentukan daerah mana yang seharusnya terlebih dahulu di prioritaskan dalam pembangunan sistem irigasi. Dan juga Saat ini penentuan prioritas pengerjaan pembangunan irigasi yang ada masih bersifat manual. Sehingga proses penentuan prioritasnya harus dilakukan oleh ahli dan membutuhkan waktu, pikiran dan tenaga yang cukup banyak. Selain itu hasil output prioritasnya terkadang masih terdapat kesalahan dikarenakan kesalahan perhitungan bobotnya.

Berdasarkan dari data Dinas PSDA Kabupaten Pesisir Selatan data yang tercatat, dimana Sumber air sungai di Provinsi Sumatera Barat berasal dari pegunungan dan danau. Dengan terdapatnya keterbatasan sumber air yang sangat cukup jauh dari daerah pertanian yang ada. Maka dibutuhkan sebuah sistem yang dapat membantu dalam pengambilan keputusan untuk pembangunan sistem irigasi. Salah satu solusi untuk mengatasi permasahan ini adalah dengan menggunakan sistem yang me implementasikan kecerdasan buatan. Secara umum kecerdasan buatan adalah mesin yang mampu berfikir, menimbang tindakan yang akan diambil, dan mengambil keputusan seperti halnya manusia. Jaringan Syaraf Tiruan merupakansistem yang dapat mengubah strukturnya untuk memecahkan masalah berdasarkan informasi eksternal maupun internal yang mengalir melalui jaringan tersebut. Oleh karena sifatnya yang adaptif , JST juga sering disebut jaringan adaptif. Secara sederhana, JST adalah sebuah alat pemodelan data statistic non-liner. Jaringan Syaraf mensimulasi struktur proses-proses otak (fungsi syaraf biologis) dan kemudian membawanya kepada perangkat lunak kelas baru yang dapat mengenali pola-pola yang kompleks serta belajar dari pengalaman masa lalu (Suyanto, 2014).

Berdasarkan penelitian terdahulu dalam kajian Jaringan Syaraf Tiruan dengan algoritma Perceptron yang membahas tentang analisa gizi buruk menjelaskan bahwa Algoritma JST yang digunakan untuk menganalisa pengaruh gizi buruk terhadap perkembangan balita dapat diperoleh bentuk hasil yang dapat melakukan analisa pada pengaruh gizi buruk terhadap perkembangan balita sesuai dengan pola jaringan yang sudah ditentukan dalam melakukan penganalisaan. kemudian untuk sumber inputan yang ada pada sistem ini berupa data dari balita yang sudah di analisa serta dapat digunakan juga untuk variabel dalam jaringan (Yanto, 2018). 
Kemudian dalam kasus penelitian yang sama, Algoritma JST yang digunakan untuk menganalisa pengaruh gizi buruk terhadap perkembangan balita adalah algoritma Perceptron. Algoritma Perceptron merupakan bentuk jaringan syaraf yang digunakan untuk mengklasifikasikan suatu pola tertentu yang sering dikenal dengan pola pemisahan secara linier. Algoritma yang digunakan oleh aturan Perceptron ini akan mengatur parameter-parameter bebasnya melalui proses pembelajaran (Pujiyanta Ardi dan Fernandya Riski Hartantri, 2014).

Dalam penelitian yang berbeda (Musli Yanto, 2017), Pada sistem Jaringan Syaraf Tiruan yang telah dibangun dapat melakukan analisa pada penentuan status kelulusan siding skripsi khususnya pada mahasiswa berdasarkan data input yang sudah ditentukan dan Sistem Jaringan Syaraf Tiruan dengan algoritma perceptron ini dapat membantu dalam memastikan untuk pengambilan keputusan agar proses penentuan kelulusan sidaing skripsi tidak mengalami kesalahan dalam pengambilan keputusan.

Permasalahan yang sudah dipaparkan nantinya akan dilanjutkan dalam pembahasan dalam kajian penelitian ini dimana Jaringan Syaraf Tirian yang dirancang dengan menggunakan algoritma Perceptron ini nantinya dapat memberikan sebuah hasil keputusan dalam pembangunan sistem irigasi di Dinas PSDA Kabupaten Pesisir Selatan Provinsi Sumatera Barat.

\section{RUANG LINGKUP}

Dalam penelitian ini penulis membatasi kajian penelitian yang mencakup dalam ruang lingkup serta bertujuan untuk membatasi permasalah yang akan dibahas yakni proses penentuan pola sistem irigasi dengan menggunakan Jaringan Syaraf Tiruan Algoritma Perceptron. Dalam penentuan pola sistem irigasi ini penulis mengambil beberapa variabel diantranya : K1 = Luasan Lahan Pertanian, K2 = Kedekatan Pembangunan Irigasi Terhadap Saluran Primer/ Sungai, K3 = Potensi Pertanian daerah dan K4 = Sumber Daya Manusia.

Variabel-variabel ini nantinya akan digunakan untuk menentukan pola pembangunan sistem irigasi yang berada di daerah Kabupaten Pesisir Selatan Provinsi Sumatera Barat. Hasil yang akan diberikan dan dapat disajikan berupa pola keputusan untuk pembangunan sistem irigasi itu sendiri yang akan membantu Dinas (PSDA) dalam pengambilan keputusan.

\section{BAHAN DAN METODE}

Bahan dan metode yang digunakan dalam penelitian ini adalah sebagai berikut :

\subsection{Jaringan Syaraf Tiruan}

Jaringan Syaraf Tiruan merupakan salah satu upaya manusia dalam melaksanakan tugas tertentu. Pemodelan ini didasari oleh kemampuan otak manusia dalam mengorganisasikan sel-sel penyusunnya yang disebut neuron, sehingga mampu melaksanakan tugas -tugas tertentu, khususnya pengenalan pola dengan efektivitas yang sangat tinggi, Pola dimana neuron-neuron pada JST disusun berhubungan erat dengan algoritma belajar yang digunakan untuk melatih jaringan (Diyah Puspitaningrum: 2006):

Hermawan (Hermawan, 2006) menjelaskan bahwa jaringan syaraf tiruan adalah sistem komputasi yang arsitekturnya diilhami dari cara kerja sel syaraf biologis otak manusia.

\subsection{Algoritma Perceptron}

Metode yang digunakan dalam pengembangan ini adalah jaringan syaraf tiruan dengan menggunakan perceptron. Model ini merupakan model yang memiliki aplikasi danpelatihan yang lebih baik pada era tersebut. Perceptron merupakan salah satu bentukjaringan syaraf tiruan yang sederhana. Metode perceptron merupakan metode pembelajaran dengan pengawasan dalam sistemjaringan syaraf. Dalam merancang jaringan neuron yang perlu diperhatikan adalah banyaknya spesifikasi yang akan diidentifikasi. Jaringan neuron terdiri dari sejumlah neuron dan sejumlah masukan (Lucky Lhaura Van FC,2016).

Perceptron adalah bentuk paling sederhana dari JST yang digunakan untuk mengkasifikasikan pola khusus yang biasa disebut linearly separable, yaitu polapola yang terletak pada sisi yang berlawanan pada suatu bidang. Pada dasarnya Perceptron terdiri dari neuron tunggal dengan bobot-bobot sinaptik dan threshold yang dapat diatur, Perceptron terbatas hanya untuk mengklasifikasikan dua kelas saja (Suyanto, 2014).

\subsection{Pelatihan Perceptron}

Misalkan $s$ adalah vektor masukan dan $t$ adalah target keluaran, $\alpha$ adalah laju pemahaman (learning rate) yang ditentukan, $\theta$ adalah threshold yang ditentukan; maka algoritma pelatihan perceptron adalah sebagai berikut : Inisialisasi semua bobot $(w)$ dan bias $(b)$. Tentukan laju pemahaman $(\alpha)$. Untuk penyederhanaan, biasanya $\alpha$ diberi nilai 1 . Selama ada elemen vektor masukan yang respon unit (Fernandya Riski Hartantri Dan Ardi Pujiyanta, 2014) :

$$
\begin{aligned}
& \mathrm{y}=\left\{\begin{array}{l}
1 \text { Jika } \mathrm{y}_{-} \text {in }>\Theta \\
0 \text { Jika }-\Theta \leq \mathrm{y} \_ \text {in } \leq \Theta \\
1 \text { Jika } \mathrm{y}_{-} \text {in }<-\Theta
\end{array}\right. \\
& \text { wi(baru })=\mathrm{wi}(\text { lama })+\Delta \mathrm{w}(\mathrm{i}=1, \ldots, \mathrm{n}) \\
& \text { dengan } \Delta \mathrm{w}=\alpha \mathrm{txi} \\
& \mathrm{b}(\text { baru })=\mathrm{b}(\text { lama })+\Delta \mathrm{b} \\
& \text { dengan } \Delta \mathrm{b}=\alpha \mathrm{t}
\end{aligned}
$$

Besarnya impuls yang diterima oleh Y mengikuti fungsi aktivasi $\mathrm{y}=\mathrm{f}($ net$)$. Apabila nilai aktivasi cukup kuat, maka sinyal akan diteruskan. Nilai fungsi aktivasi (keluaran model jaringan) juga dapat dipakai sebagai dasar untuk mengubah bobot (Muhamad Arifin dkk, 2018). 


\section{PEMBAHASAN}

Berikut pembahasan pada penelitian yang membahas masalah dalam penentuan pola pembangunan sistem irigasi pada Dinas PSDA. Berikut pembahasan yang dibahas:

\subsection{Analisa Data}

Proses penganalisaan data yaitu dimana data tersebut berupa variabel-variabel yang digunakan sebagai penentuan pola sistem pembangunan irigasi di daerah yang akan dibangun. Adapun metode yang digunakan dalam menganalisa data ini adalah dengan menerapkan metode Jaringan Syaraf Tiruan Algoritma Perceptron bertujuan untuk memberikan solusi berupa informasi yang dapat mendukung dalam pengambilan keputusan. Adapun variabel yang akan digunakan meliputi:

1. Permasalahan : Menentukan Daerah Yang Akan Dibangun Sistem Irigasi

2. Kriteria : Berikut adalah yang menunjukan kriteria yang akan di analisa dan diproses dengan menggunkan metode ANP : K1=Luasan Lahan Pertanian, K2=Kedekatan Pembangunan Irigasi Terhadap Saluran Primer/ Sungai, K3=Potensi Pertanian daerah dan K4=Sumber Daya Manusia.

Keterangan Istilah:

1. Luasan Lahan Pertanian, yaitu salah satu kriteria dalam pembuatan sistem irigasi, dimana luasan pertanian tersebut dinyatakan dalam satuan hektare.

2. Kedekatan Pembangunan Irigasi Terhadap Saluran Primer/ Sungai, merupakan salah satu kriteria yang digunakan, dimana dengan semakin dekat maka akan semakin mudah dalam menjangkau sumber saluran irigasi.

3. Potensi Pertanian daerah, dimana kriteria ini digunakan sbagai pertimbangan apakah dengan pembangunan irigasi akan meningkatkan potensi panen yang lebih baik atau tidak.

4. Sumber Daya Manusia, yaitu salah satu kriteria yang digunakan sebagai pertimbangan, dimana dengan sumber daya manusai yang memadai akan memaksimalkan pemamfaatan irigasi yang akan dibangun.

Adapun data yang akan dilakukan proses penentuan pola Sistem Irigasi yang akan dibangun dengan metode Jaringan Syaraf Tiruan Algoritma Perceptron sebagai berikut:

Tabel 1. Data Variabel Jaringan Perceptron

\begin{tabular}{|l|l|l|l|l|}
\hline \multicolumn{1}{|c|}{$\begin{array}{c}\text { Nama } \\
\text { Daerah }\end{array}$} & \multicolumn{1}{|c|}{ K1 } & K2 & K3 & K4 \\
\hline $\begin{array}{l}\text { Kecamatan } \\
\text { Bayang }\end{array}$ & $>9 \mathrm{Ha}$ & Dekat & $\begin{array}{l}\text { Sangat } \\
\text { Bagus }\end{array}$ & $\begin{array}{l}\text { Sangat } \\
\text { Memadai }\end{array}$ \\
\hline $\begin{array}{l}\text { Kecamatan } \\
\text { Tarusan }\end{array}$ & $\begin{array}{l}3-9 \\
\mathrm{Ha}\end{array}$ & Jauh & $\begin{array}{l}\text { Sangat } \\
\text { Bagus }\end{array}$ & Memadai \\
\hline $\begin{array}{l}\text { Kecamatan } \\
\text { Ampek } \\
\text { Jurai }\end{array}$ & $\begin{array}{l}3-9 \\
\mathrm{Ha}\end{array}$ & Dekat & Cukup & Memadai \\
\hline $\begin{array}{l}\text { Kecamatan } \\
\text { Kambang }\end{array}$ & $\begin{array}{l}3-9 \\
\mathrm{Ha}\end{array}$ & Dekat & Bagus & Memadai \\
\hline $\begin{array}{l}\text { Kecamatan } \\
\text { Tapan }\end{array}$ & $>9 \mathrm{Ha}$ & $\begin{array}{l}\text { Sangat } \\
\text { Dekat }\end{array}$ & Cukup & $\begin{array}{l}\text { Sangat } \\
\text { Memadai }\end{array}$ \\
\hline
\end{tabular}

\begin{tabular}{|l|l|l|l|l|}
\hline $\begin{array}{l}\text { Kecamatan } \\
\text { Inrdapura }\end{array}$ & $>9 \mathrm{Ha}$ & $\begin{array}{l}\text { Sangat } \\
\text { Dekat }\end{array}$ & $\begin{array}{l}\text { Sangat } \\
\text { Bagus }\end{array}$ & $\begin{array}{l}\text { Sangat } \\
\text { Memadai }\end{array}$ \\
\hline $\begin{array}{l}\text { Kecamatan } \\
\text { Batang } \\
\text { Kapeh }\end{array}$ & $\begin{array}{l}3-9 \\
\mathrm{Ha}\end{array}$ & Jauh & Cukup & Memadai \\
\hline
\end{tabular}

\subsection{Proses Perhitungan Algoritma Perceptron}

Permasalahan yang akan dibahas dalam penelitian ini adalah mengenai penentuan pola sistem pembangunan irigasi di Kabupaten Pesisir Selatan Provinsi Sumatera Barat. Proses analisa yang adalah proses sebelum dilakukannya perhitungan Jaringan yaitu dengan model Perceptron, dimana langkah awalnya adalah membangun arsitektur jaringan algoritma Perceptron. Arsitektur jaringan ini dapat digambarkan menggunakan variabelvariabel yang akan digunakan sebagai indikator penentuan pola sistem pembangunan irigasi. Adapun bentuk arsitektur Jaringan Syaraf Tiruan Algoritma Perceptron sebagai berikut:

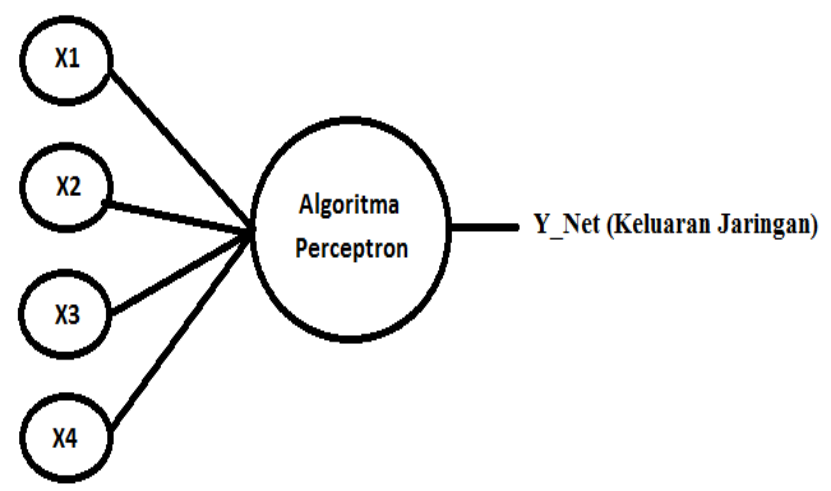

Gambar 1. Arsitektur Jaringan Perceptron

Setelah data arsitektur jaringan sudah dirancang, maka dilanjutkan pada proses transformasi terhadap variabel-variabel yang akan digunakan. Berikut hasil transformasi yang sudah dihasilkan :

Tabel 2. Data Transformasi Variabel Jaringan Perceptron

\begin{tabular}{|c|c|c|c|c|c|}
\hline No & K1 & K2 & K3 & K4 & T \\
\hline 1 & 1 & 0 & 1 & 1 & 1 \\
\hline 2 & 0 & -1 & 1 & 0 & 0 \\
\hline 3 & 0 & 0 & -1 & 0 & 0 \\
\hline 4 & 0 & 0 & 0 & 0 & 0 \\
\hline 5 & 1 & 1 & -1 & 1 & 1 \\
\hline 6 & 1 & 1 & 1 & 1 & 1 \\
\hline 7 & 0 & -1 & -1 & 0 & 0 \\
\hline
\end{tabular}

Keterangan :

$$
\begin{aligned}
& \mathrm{T}=\text { Nilai Target } \\
& 1=\text { merupakan keputusan Posistif dalam } \\
& \text { pembangunan Irigasi } \\
& 0=\text { merupakan keputusan Negatif dalam } \\
& \text { pembangunan Irigasi }
\end{aligned}
$$


Tabel 3. Keterangan Proses Transformasi

\begin{tabular}{|c|c|c|c|}
\hline \multirow{2}{*}{ K1 } & $>9 \mathrm{Ha}$ & $3-9 \mathrm{Ha}$ & \multicolumn{1}{|c}{} \\
\cline { 2 - 3 } & 1 & 0 & \\
\hline \multirow{2}{*}{ K2 } & Sangat Dekat & Dekat & Jauh \\
\cline { 2 - 3 } & 1 & 0 & -1 \\
\hline \multirow{2}{*}{ K3 } & Sangat Bagus & Bagus & Cukup \\
\cline { 2 - 3 } & 1 & 0 & -1 \\
\hline \multirow{2}{*}{ K4 } & Sangat Memadai & Memadai & \multicolumn{1}{|c}{} \\
\cline { 2 - 3 } & 1 & 0 & \multicolumn{2}{|c}{} \\
\hline
\end{tabular}

Setelah proses transformasi data dilakukan, penulis melanjutkan proses pada tahapan perhitungan algoritma perceptron. Sebelum memulai perhitungan, hal yang mesti diperhatikan adalah menentukan nilai bobot, dan bias serta nilai treshold yang nantinya digunakan sebagai nilai batas toleransi dari hasil output keluaran jaringan (Y_net). Berikut nilai bobot, bias dan treshold secara default :

Tabel 4. Nilai Bobot dan Bias Default

\begin{tabular}{|c|c|c|c|c|}
\hline \multicolumn{4}{|c|}{ Nilai Bobot } & $\begin{array}{l}\text { Nilai } \\
\text { Bias }\end{array}$ \\
\hline v1.1 & $\mathrm{v1.2}$ & $\mathrm{v1.3}$ & v1.4 & $\mathbf{b}$ \\
\hline 0 & 0 & 0 & 0 & 0 \\
\hline
\end{tabular}

Setelah didapatkan nilai bobot, bias dan treshold maka penulis melanjutkan tahapan perhitungan algoritma Percepron. Adapan proses perhitungan yang dilakukan mengunakan data pertama guna implementasi algoritma perceptron berikut :

$$
\begin{aligned}
& \text { y_in }=\quad \begin{array}{l}
\mathrm{b}+((\mathrm{X} 1 * \mathrm{v} 1.1)+(\mathrm{X} 2 * \mathrm{v} 1.2)+(\mathrm{X} 3+\mathrm{v} 1.3)+ \\
(\mathrm{zX} 4 * \mathrm{v} 1.4))
\end{array} \\
& =0+((1 * 0)+(0 * 0)+(1+\mathrm{v} 0)+(1 * 0)) \\
& =0+(0+0+0+0) \\
& =0 \\
& \text { y_net }=\quad \text { Jika Nilai }=1 \text { Maka }\left(y \_ \text {in }=1>\Theta=0.5\right) \\
& \text { Jika Nilai }=0 \text { Maka }(-\bar{\Theta}=-0.5 \leq \text { y_in }=0 \\
& \leq \Theta=0.5 \text { ) } \\
& \text { Jika Nilai }=-1 \text { Maka }\left(y \_ \text {in }=0<\Theta=0.5\right)
\end{aligned}
$$

\section{Ketentuan}

Tidak Sesuai Karena nilai y_in $=0$

Sesuai Karena nilai y_in $=0$

Tidak Sesuai Karena $y \_i n=0$ kecil dari treshold $\Theta=0.5$

Hasil keluaran jaringan $y \_n e t \neq y \_i n ~(1 \neq 0)$

Setelah proses perhitungan algoritma didapat, maka lihat apakah hasil keluaran jaringan $y_{-}$net sudah sama dengan $y_{-}$in. Jika nilai keluaran tidak sama, maka lakukan proses update nilai bobot dan bias. Setelah nilai bobot dan bias sudah berubah, lakukan proses pencarian y_net berulang-ulang (Epoch) sampai hasil keluaran jaringan y_net sudah sama dengan y_in. Dalam proses perhitungan algoritma perceptron ini penulis menggunakan alat bantu yakni Software Matlab.

Software Matlab digunakan untuk membantu penulis dalam melihat proses algoritma perceptron yang terjadi dalam pencarian (Epoch). Berikut bentuk penggunaan Software Matlab dalam perhitungan algoritma perceptron

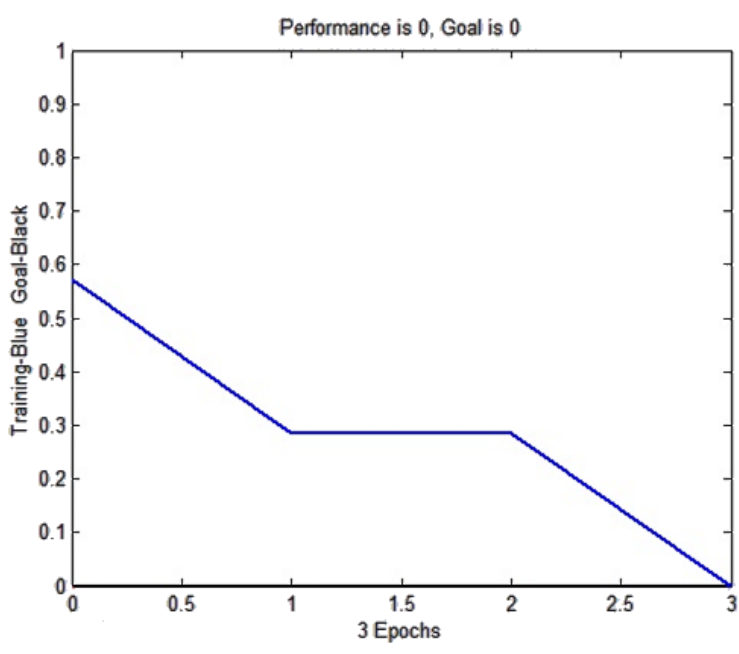

Gambar 2. Hasil Grafik Epoch yang dihasilkan

Pada hasil tampilan di atas dapat dijelaskan bahwa proses penentuan pola pembangunan sistem irigasi air yang ada di daerah Kabupaten Pesisir Selatan Provinsi Sumatera Barat ini dapat diolah dengan menggunakan Software Matlab, sehingga hasil keluaran jaringan serta nilai bobot dan bias baru yang didapat akan digunakan dan diterapkan kedalam sebuah aplikasi yang nantinya dapat membantu pihak Dinas Pengelolaan Sumber Daya Air Kabupaten Pesisir Selatan dalam pengambilan keputusan untuk pembangunan sistem irigasi air.

\section{KESIMPULAN}

Kesimpulan dari penelitian dalam penentuan pola sistem irigasi lahan pertanian adalah sebagai berikut : Dengan menggunakan Jaringan Syaraf Tiruan algoritma Perceptron ini dapat mampu mengenali pola sistem irigasi lahan pertanian yang berada di daerah Kabupaten Pesisir Selatan Provinsi sumatera barat dengan mengacu kepada variabel-variabel yang digunakan yakni K1 = Luasan Lahan Pertanian, K2 = Kedekatan Pembangunan Irigasi Terhadap Saluran Primer/ Sungai, K3 = Potensi Pertanian daerah dan K4 = Sumber Daya Manusia. Proses yang dilakukan dalam algoritma Perceptron ini dimulai dari mentransformasi variabel yang digunakan, setelah itu dilanjutkan pada proses perhitungan algoritma perceptron dengan menggunakan nilai bobot, bias serta treshold guna melihat hasil keluaran jaringan dan tahap akhir dari proses ini adalah melakukan pelatihan terhadap jaringan yang telah dibangun. Nilai keluaran jaringan dengan menggunakan algoritma Perceptron akan dijadikan sebuah masukan pada Dinas Pengelolaan Sumber Daya Air Kabupaten Pesisir Selatan adalah kesulitan untuk menentukan daerah mana yang seharusnya terlebih dahulu dalam pembangunan sistem irigasi air pada lahan pertanian.

\section{SARAN}

Guna mencapai kesempurnaan dalam penelitian ini, penulis memilik saran dari penelitian yang sudah dilakukan. Berikut saran yang penulis sampaikan : Dalam penelitian ini sebaiknya sampai pada tahapan pembangunan sebuah aplikasi agar nantinya pihak Dinas Pengelolaan Sumber Daya Air Kabupaten Pesisir Selatan 
mudah dalam mengelola dan memutuskan sebuah keputusan dalam pembangunan sistem irigasi air. Dalam permasalahan ini nantinya bisa dilanjutkan lagi ke penelitian berikutnya dengan mengambil beberapa variabel-variabel yang lebih lengkap sesuai dengan fakta yang ada agar keputusan yang dihasilkan bisa lebih tepat dan akurat. Pada penelitian kedepanya, penulis menyarankan untuk melakukan beberapa pengujian dengan metode lain selain Jaringan Syaraf Tiruan algoritma Perceptron dalam masalah pengenalan pola sistem irigasi air.

\section{DAFTAR PUSTAKA}

Arifin, Muhamad, 2018 Aplikasi Jaringan Saraf Tiruan Metode Perceptron Pada Pengenalan Pola Notasi, Jurnal SIMETRIS, Vol. 9 No. 1

David. Perancangan Perangkat Lunak Pengenalan PolaKarakter Menggunakan Jaringan Syaraf Tiruan Perceptron. 2011. Jurnal Ilmiah SISFOTENIKA. 1(1): 10-19.

Diyah Puspitaningrum, 2006, Pengantar Jaringan Syaraf Tiruan, Yogyakarta: ANDI.

Fc. Lucky Laura Van, 2016, Klasifikasi Gaya Belajar Visual-Audiotorykinesthetic (V-A-K) Mahasiswa Berbasis Jstmenggunakan Algoritma Perceptron, Jurnal Teknologi Informasi \& Komunikasi Digital Zone, Volume 7 , Nomor 1.

Fernandya Riski Hartantri Dan Ardi Pujiyanta, 2014, "Deteksi Penyakit Dan Serangan Hama Tanaman Buah Salak Menggunakan Jaringan Syaraf Tiruan (Jst) Dengan Metode Perceptron", Urnal Sarjana Teknik Informatika E-Issn: 2338-5197 Volume 2 Nomor 2.

Hermawan, Arif. 2006. Jaringan Saraf Tiruan Teori dan Aplikasi, Yogyakarta: Andi

Pujiyanta Ardi, 2009, Pengenalan Citra Objek Sederhana Dengan Jaringan Syaraf Tiruan Metode Perceptron, Jurnal Informatika Vol. 3, No. 1.
Sovi, Rini \& Yanto, Musli, 2018 Jaringan Syaraf Tiruan Analisa Pengaruh Gizi Buruk Terhadap Perkembangan Balita Algoritma Perceptron, MEDIASISFO : Vol.12, No.4, April 2018

Suyanto, 2014, Artificial Intelligence ( Searching, Reasoning, Planning dan Learning), Bandung: INFORMATIKA.

Yanto, Musli, 2017, Penerapan Jaringan Syaraf Tiruan Dengan Algoritma Perceptron Pada Pola Penentuan Nilai Status Kelulusan Sidang Skripsi. Jurnal TeknoIf Vol. 5 No. (2), ITP Padang. 